\title{
ChemComm
}

\section{A BODIPY aldoxime-based chemodosimeter for highly selective and rapid detection of hypochlorous acid $\dagger$}

Cite this: Chem. Commun., 2013, 49, 7836

Received 14th June 2013,

Accepted 4th July 2013

DOI: $10.1039 / c 3 c c 44463 e$

www.rsc.org/chemcomm

A BODIPY-based fluorescent probe integrated with an aldoxime unit shows a remarkable fluorescence "turn-on" response to hypochlorous acid ( $\mathrm{HOCl})$. The oxidative dehydrogenation of BODIPY aldoxime by $\mathrm{HOCl}$ results in a distinct fluorescence enhancement as well as a change in color from red to orange.

Hypochlorous acid (HOCl) is a biologically important reactive oxygen species (ROS) produced in living organisms from hydrogen peroxide and chloride ions in a reaction catalyzed by the heme-enzyme myeloperoxidase (MPO). ${ }^{1} \mathrm{HOCl}$ has a critical role as an antimicrobial agent in the natural defense system. ${ }^{2}$ It is endogenously generated in cellular environments to kill invading bacterial pathogens. Excessive production of $\mathrm{HOCl}$, however, leads to the oxidation of biomolecules which results in tissue damage and various diseases such as atherosclerosis, ${ }^{3}$ arthritis, ${ }^{4}$ and cancer. ${ }^{5}$

Scientists are performing extensive research to elucidate the mechanism by which HOCl kills bacteria and destroys human tissue. Nevertheless, the detailed understanding of $\mathrm{HOCl}$ formation during pathogenic biological events still remains a challenge due to the lack of methods for monitoring $\mathrm{HOCl}$ in living organisms. Sensitive and accurate detection methods for hypochlorous acid that function in living samples are thus highly demanded for the research in biology and medicine.

Fluorescence sensing methods in this context are highly promising as they allow the possibility of real-time visual detection of analytes both in solution and living organism. In recent years, a variety of fluorescent probes have been developed for detection of $\mathrm{HOCl}$, most of which exploit the strong oxidation properties of HOCl. ${ }^{6}$ Functional groups, sensitive to hypochlorite oxidation, such as $p$-methoxyphenol, ${ }^{7}$ dibenzoylhydrazine, ${ }^{6 f}$ thiol ${ }^{6 d}$ selenide, ${ }^{6 a-c}$ oxime $^{8}$ and $p$-alkoxyaniline ${ }^{9}$ have been extensively utilized in the probe design. Some of these probes, however, show $\mathrm{pH}$ dependency and function only under basic conditions ( $\mathrm{pH}>9.0)$, which is an undesired feature for cell imaging

Department of Chemistry, Faculty of Science, İmir Institute of Technology (IZTECH), Urla 35430, Izmir, Turkey. E-mail: mustafaemrullahoglu@iyte.edu.tr $\dagger$ Electronic supplementary information (ESI) available: Synthesis and characterization of the probe, and all data for UV-Vis and fluorescence titrations. See DOI: $10.1039 / \mathrm{c} 3 \mathrm{cc} 44463 \mathrm{e}$ studies. In addition to this, there are common shortcomings that undermine their general applicability, including cytotoxicity, low sensitivity, slow response time, selectivity and cross-sensitivity towards other species. Thus, it is of considerable interest to design and develop new probes able to overcome these limitations.

In this work, we have designed a novel BODIPY (boron-dipyrromethene) based fluorescent probe integrated with an aldoxime unit (Bodipy-OX) for selective detection of $\mathrm{HOCl}$ in various environments. The oxime functionality has been well established as a sensitive group to hypochlorous acid and thus provides a suitable signalling platform in the design of fluorescent probes. ${ }^{8}$ The BODIPY fluorophore was chosen as the signal reporter because of its exceptional photophysical properties such as long excitation/emission wavelengths, high molar absorption coefficients and fluorescence quantum yield. ${ }^{10}$

Bodipy-OX was prepared using the synthetic route outlined in Scheme 1. A Vilsmeier-Haack formylation reaction of Bodipy gave Bodipy-AL which was further treated with $\mathrm{NH}_{2} \mathrm{OH} \cdot \mathrm{HCl}$ in EtOH at reflux temperature to yield Bodipy-OX. After chromatographic purification, the structure of Bodipy-OX was confirmed using NMR spectroscopy and mass spectrometry. ${ }^{11}$

We commenced our investigation by first examining the parameters of the sensing media. Among various solvent systems tested, a combination of $\mathrm{H}_{2} \mathrm{O}-\mathrm{DMF}(4: 1, \mathrm{v} / \mathrm{v})$ proved to be highly efficient for the sensing process. ${ }^{11}$ The spectral properties of the probe towards the addition of $\mathrm{HOCl}$ were examined under simulated physiological conditions phosphate buffer-DMF ( $\mathrm{pH} 7.2$, v/v, $4: 1$ ). The plot of the fluorescence intensity of Bodipy-OX against the increase in $\mathrm{HOCl}$ concentration is displayed in Fig. 1a. As shown, Bodipy-OX in solution is almost non-emissive $\left(\Phi_{\mathrm{F}}=0.03\right)$ possibly due to a non-radiative deactivation through rapid isomerization of the $\mathrm{C}=\mathrm{N}-\mathrm{OH}$ group.

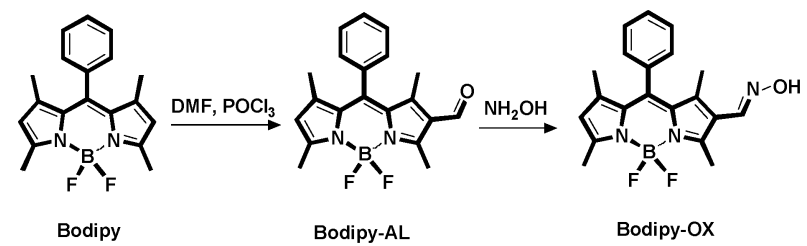

Scheme 1 Synthesis of Bodipy-OX. 

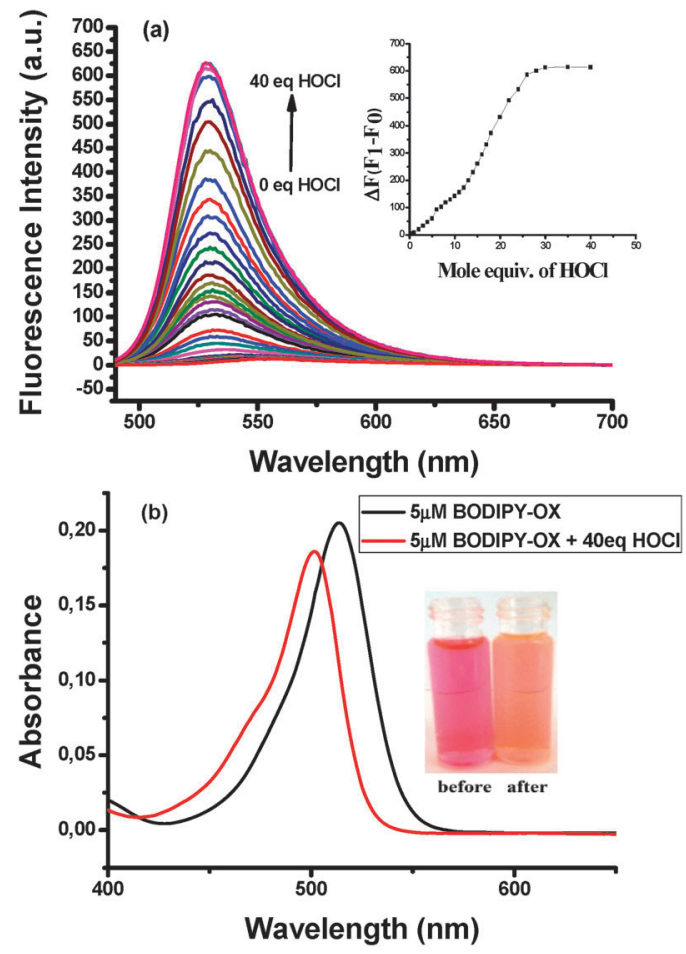

Fig. 1 (a) Fluorescence spectra of Bodipy-OX $(5.0 \mu \mathrm{M})+\mathrm{HOCl}(0.5$ to $200 \mu \mathrm{M}$, 0.1 to 40 equiv.) in $\mathrm{pH} 7.2$ buffer-DMF $(v / v, 4: 1)\left(\lambda_{\text {ex }}: 470 \mathrm{~nm}\right)$. Inset: fluorescence intensity changes of Bodipy-OX vs. equivalents of $\mathrm{HOCl}$. (b) Absorption spectra of Bodipy-OX $(5.0 \mu \mathrm{M})$ and Bodipy-OX $+\mathrm{HOCl}(200 \mu \mathrm{M}, 40$ equiv. $)$ Inset: the colorimetric detection of $\mathrm{HOCl}$.

However, the addition of HOCl to the solution of Bodipy-OX resulted in a significant enhancement of the emission intensity positioned at $529 \mathrm{~nm}$. The emission intensity reached its maximum when 40 equiv. of $\mathrm{HOCl}$ was added, with an enhancement factor over 48-fold. Notably, the spectroscopic response of the probe was extremely fast and complete saturation of the signal intensity was observed within seconds (Fig. S10, ESI + ). There was a linear dependence of the fluorescence intensity on the $\mathrm{HOCl}$ concentration $(0.5$ to $200 \mu \mathrm{M}$, 0.1 to 40 equiv.) and the minimum amount of $\mathrm{HOCl}$ that can be detected has been evaluated to be $0.5 \mu \mathrm{M}$ (LOD). Meanwhile, upon addition of HOCl to the solution of Bodipy-OX, a new absorption band centered at $502 \mathrm{~nm}$ which was shifted to a slightly shorter wavelength (blue shift) as compared with the absorbance of Bodipy-OX $(\lambda=514 \mathrm{~nm}$ ), (see Fig. 1b and Fig. S2b, ESI + ). All spectroscopic changes were observed immediately upon the addition of $\mathrm{HOCl}$, indicating that the oxidation reaction occurred rapidly at room temperature. The addition of $\mathrm{HOCl}$ to the probe solution developed an instantaneous color and fluorescence change which was easily detectable by the naked eye under light and UV irradiation.

The $\mathrm{pH}$-dependence of Bodipy-OX in the detection of $\mathrm{HOCl}$ was investigated carefully. Bodipy-OX was stable and weakly fluorescent $\left(\Phi_{\mathrm{F}}=0.03\right)$ over a wide $\mathrm{pH}$ range $(\mathrm{pH} 3.0$ to 11.0$)$. On the other hand, the fluorescence response of the probe towards the addition of $\mathrm{HOCl}$ was indeed $\mathrm{pH}$ dependent. Bodipy-OX displayed an efficient fluorescence response to $\mathrm{HOCl}$ in the $\mathrm{pH}$ range of 4.0-9.0. However, the fluorescence response decreased sharply at $\mathrm{pH}>9.0$, which was an indication that the active species detected was the hypochlorous acid ( $\mathrm{HOCl})$ rather than the hypochlorite ion $\left(\mathrm{OCl}^{-}\right)$. Eventually, it turned out that Bodipy-OX can be efficiently used for the detection of $\mathrm{HOCl}$ in a wide $\mathrm{pH}$ range ( $\mathrm{pH} 4-9)$. Notably, the fluorescence enhancement was significantly greater at physiological $\mathrm{pH}(\mathrm{pH}=7.2)$, which suggests that Bodipy-OX is highly suitable for biological applications.

It was important to rule out the possible involvement of other reactive species in the sensing process. Therefore, the titration of Bodipy-OX with various other ROS, metal ions and also anions was carried under the same sensing conditions. To our delight, related ROS such as $\mathrm{H}_{2} \mathrm{O}_{2},{ }^{\bullet} \mathrm{OH}, \mathrm{ROO}^{\bullet}$ and ions including $\mathrm{Mg}^{2+}, \mathrm{Zn}^{2+}, \mathrm{Cu}^{2+}$, $\mathrm{CO}_{3}{ }^{2-}, \mathrm{F}^{-}, \mathrm{I}^{-}, \mathrm{AcO}^{-}, \mathrm{NO}_{3}{ }^{-}, \mathrm{NO}_{2}{ }^{-}, \mathrm{SO}_{4}{ }^{2-}, \mathrm{ClO}_{3}{ }^{-}$did not mediate any chemical reaction to result in a spectroscopic response. As displayed in Fig. S5 (ESI $\dagger$ ), only the addition of $\mathrm{HOCl}$ resulted in an enhancement of fluorescence at $529 \mathrm{~nm}$, which implied the high selectivity of Bodipy-OX to $\mathrm{HOCl}$.

In order to assess any possible interference by other analytes we explored the fluorescence response of Bodipy-OX towards $\mathrm{HOCl}$ ( $200 \mu \mathrm{M}, 40$ equiv.) in the presence of the other ROS and metal ions $(200 \mu \mathrm{M}, 40$ equiv.). As shown in Fig. S6 (ESI $\dagger$ ), the tested analytes displayed no interference with the detection of $\mathrm{HOCl}$.

In order to get insight into the sensing mechanism we focused on the reaction products formed by treating the probe with $\mathrm{HOCl}$ under the sensing conditions $\left(\mathrm{DMF}-\mathrm{H}_{2} \mathrm{O}(\mathrm{v} / \mathrm{v}, 1: 4)\right)$. The reaction quantitatively afforded one major product in a short reaction time (5 min) as identified using TLC. The crude product was successfully purified using flash column chromatography and the structure of the isolated product was confirmed using ${ }^{1} \mathrm{H}-\mathrm{NMR},{ }^{13} \mathrm{C}-\mathrm{NMR}$ and mass analysis (Maldi-TOF-TOF).

Aldoximes are reported in the literature to give the corresponding aldehyde $^{8 a-c}$ or the carboxylic $\operatorname{acid}^{8 d}$ upon oxidation with $\mathrm{HOCl}$ depending on the reaction medium. Surprisingly, the only product isolated was a nitrile oxide derivative of the BODIPY core (Scheme 2). Mass analysis confirmed the formation of a BODIPY-nitrile oxide (Bodipy-CNO, $\mathrm{m} / \mathrm{z}=365.173$ found, 365.151 calc.) in the solution.

The majority of nitrile oxides are, in general, unstable and thus difficult to isolate and purify. ${ }^{11}$ Surprisingly, the BODIPY based nitrile oxide (Bodipy-CNO) showed an unexpected stability presumably due to the extended conjugation and steric shielding of the nitrile oxide group. To our delight, Bodipy-CNO was successfully isolated (rapid chromotography through a short pad of silica) and characterized using NMR spectroscopy. As shown in the ${ }^{1} \mathrm{H}-\mathrm{NMR}$ spectrum of the isolated product (Fig. 2), the aldoxime and the hydroxyl proton signal at $10.47 \mathrm{ppm}$ and $8.07 \mathrm{ppm}$ disappeared upon treatment with $\mathrm{HOCl}$.

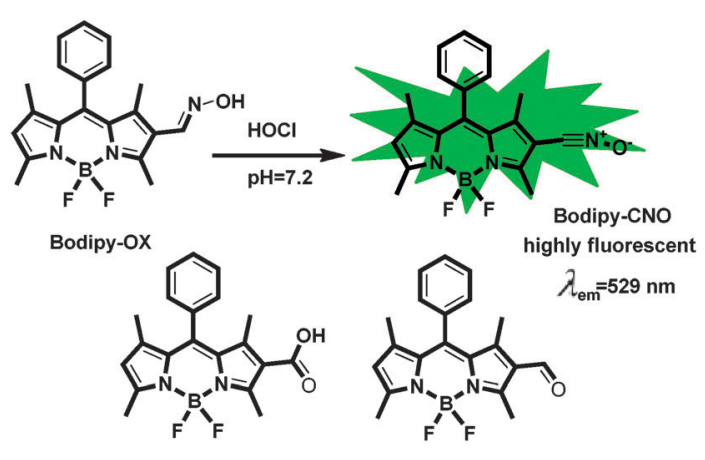

(not formed) (not formed) $\lambda_{\mathrm{em}}=507 \mathrm{~nm}$

Scheme 2 Oxidative dehydrogenation of Bodipy-OX. 


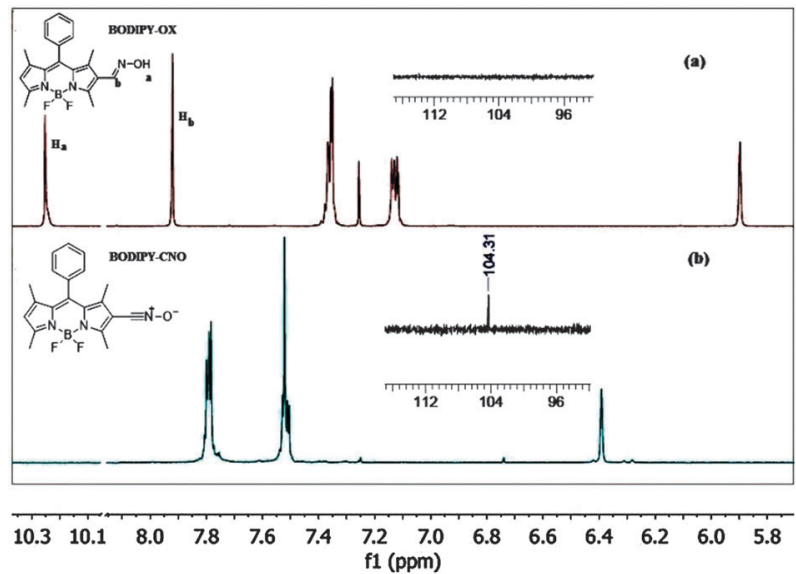

Fig. 2 (a) Partial ${ }^{1} \mathrm{H}$ NMR spectra of Bodipy-OX, (b) Bodipy-CNO; inset: partial ${ }^{13} \mathrm{C}$ NMR spectra of (a) Bodipy-OX, (b) Bodipy-CNO.

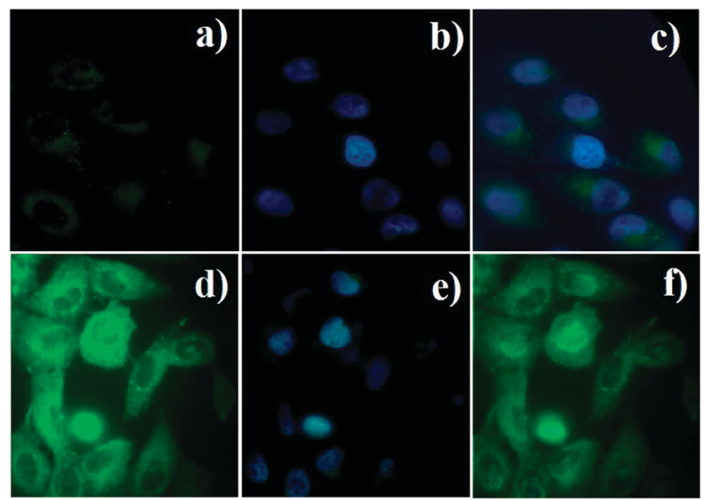

Fig. 3 (a) Fluorescence image of cells treated with only probe $(1 \mu \mathrm{M})$ for $10 \mathrm{~min}$; (b) fluorescence image of cells treated with Hoechst-34580 (1 $\mu \mathrm{M})$; (c) merged image of frames a and b; (d) fluorescence image of cells treated with $\mathrm{HOCl}$ $(10 \mu \mathrm{M}),\left(\lambda_{\text {ex: }} 470 \mathrm{~nm}\right)$; (e) fluorescence image of cells treated with $\mathrm{HOCl},\left(\lambda_{\text {ex }}\right.$ : $350 \mathrm{~nm}) ;(f)$ merged image of frames $d$ and $e$.

Moreover, the ${ }^{13} \mathrm{C}-\mathrm{NMR}$ spectrum displays a characteristic carbon peak at $104.31 \mathrm{ppm}$ that belongs to the nitrile oxide carbon atom.

Based on the structure of the isolated product, fully characterized using NMR spectroscopy and mass spectrometry, there was no doubt that the sensing event proceeds through an oxidative dehydrogenation of the oxime (Bodipy-OX) generating a highly fluorescent and sensitive nitrile oxide $\left(\Phi_{\mathrm{F}}=0.86\right)$.

It is worth noting that in the solution Bodipy-CNO decomposes into unidentifiable products. The decomposition of Bodipy-CNO was also confirmed using fluorescence spectrometry. As displayed in Fig. S8 (ESI $\dagger$ ), the fluorescence intensity of the in situ formed nitrile oxide (Bodipy-CNO) was stable only for a very short period of time $(5 \mathrm{~min})$, and decreased gradually in the course of time.

Relying on the promising properties of Bodipy-OX, we next questioned the potential of the probe for tracking $\mathrm{HOCl}$ in living cells. Human Mammary Epithelial Cells (MCF10A) were incubated with Bodipy-OX $(1.0 \mu \mathrm{M})$ for $10 \mathrm{~min}$, and then stained with Hoechst-34580 $(1.0 \mu \mathrm{M})$. MCF10A cells incubated with Bodipy-OX exhibited a very weak intracellular fluorescence whereas a significant fluorescence increase was monitored in the cells after treatment with HOCl (Fig. 3d). This preliminary cell imaging study suggested that the probe is cell membrane permeable and can be efficiently used for in vitro imaging of $\mathrm{HOCl}$ in living cells.

In summary, we have developed a "turn-on" type fluorescent probe that shows remarkable fluorescence emission enhancement in response to hypochlorous acid ( $\mathrm{HOCl})$ with high sensitivity and selectivity over other ROS and metal ions. This novel probe operates through an irreversible chemical reaction and thus can be classified as a chemodosimeter. The probe has a low detection limit and operates efficiently under physiological conditions, which is of crucial importance for biological imaging studies. Besides the rapid and specific response to $\mathrm{HOCl}$, this probe can also be applied for in vitro imaging of $\mathrm{HOCl}$ in living cells.

We thank İzmir Institute of Technology (IZTECH) for financial support and Biological Mass Spectrometry and Proteomics Facility for Mass analysis. Special thanks to Ayșenur Çataler Karakuş for bio-imaging experiments.

\section{Notes and references}

1 Y. W. Yap, M. Whiteman and N. S. Cheung, Cell. Signalling, 2007, 19, 219.

2 C. C. Winterbourn, M. B. Hampton, J. H. Livesey and A. J. Kettle, J. Biol. Chem., 2006, 281, 39860.

3 S. Sugiyama, K. Kugiyama, M. Aikawa, S. Nakamura, H. Ogawa and P. Libby, Arterioscler., Thromb., Vasc. Biol., 2004, 24, 1309.

4 M. J. Steinbeck, L. J. Nesti, P. F. Sharkey and J. Parvizi, J. Orthop. Res., 2007, 25, 1128.

5 D. I. Pattison and M. J. Davies, Biochemistry, 2006, 45, 8152.

6 (a) B. Wang, P. Li, F. Yu, P. Song, X. Sun, S. Yang, Z. Lou and K. Han, Chem. Commun., 2013, 49, 1014; (b) Z. Lou, P. Li, Q. Panab and K. Han, Chem. Commun., 2013, 49, 2445; (c) S.-R. Liu and S.-P. Wu, Org. Lett., 2013, 15, 878; (d) S. Kenmoku, Y. Urano, H. Kojima and T. Nagano, J. Am. Chem. Soc., 2007, 129, 7313; (e) Y. Koide, Y. Urano, S. Kenmoku, H. Kojima and T. Nagano, J. Am. Chem. Soc., 2007, 129, 10324; $(f)$ X. Chen, X. Wang, S. Wang, W. Shi, K. Wang and H. Ma, Chem.-Eur. J., 2008, 14, 4719; $(g)$ G. Chen, F. Song, J. Wang, Z. Yang, S. Sun, J. Fan, X. Qiang, X. Wang, B. Dou and X. Peng, Chem. Commun., 2012, 48, 2949; (h) Y.-K. Yang, H. J. Cho, J. Lee, I. Shin and J. Tae, Org. Lett., 2009, 11, 859; (i) P. Panizzi, M. Nahrendorf, M. Wildgruber, P. Waterman, J. L. Figueiredo, E. Aikawa, J. McCarthy, R. Weissleder and S. A. Hilderbrand, J. Am. Chem. Soc., 2009, 131, 15739; $(j)$ K. Cui, D. Q. Zhang, G. X. Zhang and D. B. Zhu, Tetrahedron Lett., 2010, 51, 6052; ( $k$ ) X. D. Lou, Y. Zhang, Q. Q. Li, J. G. Qin and Z. Li, Chem. Commun., 2011, 47, 3189; (l) Y. Koide, Y. Urano, K. Hanaoka, T. Terai and T. Nagano, J. Am. Chem. Soc., 2011, 133, 5680; $(m)$ Y. Zhou, J. Li, K. Chu, K. Liu, C. Yao and J. Li, Chem. Commun., 2012, 48, 4677.

7 Z.-N. Sun, Z.-N. Liu, Y. Chen, P. K. H. Tam and D. Yang, Org. Lett., 2008, 10, 2171.

8 (a) J. Shi, Q. Li, X. Zhang, M. Peng, J. Qin and Z. Li, Sens. Actuators, B, 2010, 145, 583; (b) X. Cheng, H. Jia, T. Long, J. Feng, J. Qin and Z. Li, Chem. Commun., 2011, 47, 11978; (c) W. Lin, L. Long, B. Chen and W. Tan, Chem.-Eur. J., 2009, 15, 2305; (d) N. Zhao, Y.-H. Wu, R.-M. Wang, L.-X. Shia and Z.-N. Chen, Analyst, 2011, 136, 2277.

9 J. Shepherd, S. A. Hilderbrand, P. Waternan, J. W. Heinecke, R. Weissleder and P. Libby, Chem. Biol., 2007, 14, 1221.

10 (a) N. Boens, V. Leen and W. Dehaen, Chem. Soc. Rev., 2012, 41, 1130; (b) R. Ziessel, G. Ulrich and A. Harriman, New J. Chem., 2007, 31, 496; (c) A. Loudet and K. Burgess, Chem. Rev., 2007, 107, 4891; (d) G. Ulrich, R. Ziessel and A. Harriman, Angew. Chem., Int. Ed., 2008, 47, 1184.

$11 \mathrm{H}$. Feuer, Nitrile oxide, nitrone and nitronates in organic synthesis: novel strategies in synthesis, John Wiley and Sons, 2008. 